\title{
Marine Microalgae Contribution to Sustainable Development
}

\author{
Simone Merlo ${ }^{1}$, Xavier Gabarrell Durany ${ }^{1}$, Angela Pedroso Tonon ${ }^{1}$ and Sergio Rossi ${ }^{2,3}, *$ (D) \\ 1 Institut de Ciència i Tecnologia Ambientals (ICTA), Universitat Autònoma de Barcelona, \\ ICTA-ICP Building Z Campus UAB, Bellaterra, 08193 Barcelona, Spain; \\ simonefranco.merlo@e-campus.uab.cat (S.M.); Xavier.Gabarrell@uab.cat (X.G.D.); \\ angela.pedroso@uab.cat (A.P.T.) \\ 2 Dipartimento di Scienze e Tecnologie Biologiche e Ambientali (DiSTeBA), Università del Salento, \\ Campus Ecotekne, Via Monteroni s/n, 73100 Lecce, Italy \\ 3 Labomar, Universidade Federal do Ceará, Fortaleza 3207, Brazil \\ * Correspondence: sergio.rossi@unisalento.it
}

check for updates

Citation: Merlo, S.; Gabarrell Durany, X.; Pedroso Tonon, A.; Rossi, S. Marine Microalgae Contribution to Sustainable Development. Water 2021 13, 1373. https://doi.org/10.3390/ w13101373

Academic Editor: Marina Marcella Manca

Received: 12 March 2021

Accepted: 12 May 2021

Published: 14 May 2021

Publisher's Note: MDPI stays neutral with regard to jurisdictional claims in published maps and institutional affiliations.

Copyright: (c) 2021 by the authors. Licensee MDPI, Basel, Switzerland. This article is an open access article distributed under the terms and conditions of the Creative Commons Attribution (CC BY) license (https:// creativecommons.org/licenses/by/ $4.0 /)$.

\begin{abstract}
The burning of fossil fuels is an unsustainable activity, which is leading to an increase in greenhouse gases (GHGs) emissions and related global warming. Among sustainable energy sources, microalgae represent a promising alternative to fossil fuel and contribute to the achievement of important Sustainable Development Goals (SDGs). In particular, the potential contribution of marine microalgae to sustainable development is large as, among other benefits, they represent a carbon negative energy source and may be applied in many coastal areas around the world. Despite this, significant economic and technological improvements are needed in order to make microalgae biofuels viable on a large scale. This review aims to explore how and to what extent third-generation biofuels (marine microalgae, but also the latest advances in freshwater microalgae) can benefit the realization of these SDGs. From this study we concluded that the production of large-scale marine microalgae biofuels is not yet feasible from the economic perspective at a large scale. However, the cultivation of microalgae in seawater holds great potential for increasing the small to medium viability of this biofuel source. The possibilities for improvement along with the contributions to sustainable development lay the groundwork for continuing to study and apply the potential of sustainable production of microalgae bioenergy.
\end{abstract}

Keywords: biofuels; biodiesel; sustainable development goals; renewable energy; energy security; life cycle assessment; bio-economy; marine microalgae; coastal areas

\section{Introduction}

Global and climate change are among the most 21st century urgent challenges in our planet. We are confronted with a paradigm in which the needs of a growing population and the related energy and raw material use must be addressed, while at the same time trying to keep our society within the safe planetary boundaries [1]. In this sense, a set of calls for action, known as Sustainable Development Goals (SDGs), which aims to tackle the priorities of the future, has been adopted by all United Nations Member States in the 2030 Agenda for Sustainable Development. This is also reflected in many programs, as the European Green Deal, in which we search for responses to the rapid climate change impacts at all levels.

In response to the increase of global temperature, due to the burning of fossil fuels, and the increasing energy needs, a wide set of alternatives energy sources such as solar, wind and geothermal have been explored and put in practice [2]. Biofuel from forests, agriculture, and wastes has also been developed and adopted as a more sustainable and renewable alternative to fossil fuel.

Renewable energies are especially important because the transition of several sectors, such the transport, is far to be solved [3]. Even if the goal is to reduce the needs of dieselbased (fossil-fueled) transport network, we are far from a realistic solution in this regard. In 
the last two decades, microalgae are gaining importance in a framework of bio-economy as a source of biofuel and new researchers are working to make the production of microalgae a new sustainable way to provide energy for our daily activities [4]. The attractivity of microalgae as a sustainable source for next-generation biofuels is due to their fast growth rate, high lipid content, high biomass production, capacity of growing using less space and also on infertile land, in salt and wastewater and ability of using solar light and carbondioxide $\left(\mathrm{CO}_{2}\right)$ for their growth $[5,6]$. These microorganisms are also envisaged as a potential carbon stock, conforming part of the plan for climate change mitigation [7]. The research on technological, economic and environmental features of the production of microalgae biofuels is wide and mostly based on profitability indicators [8]. However, other indicators regarding the sustainability of microalgae such as their contribution to the SDGs or global and climate change are still understudied and further research is needed to understand their broader contribution to sustainable development [9]. Microalgae cultivation presents a mix of benefits for our society that goes beyond the potential to provide an additional source of energy while maintaining or improving environmental sustainability. Microalgae could contribute to sustainable development thanks to their capacity to mitigate $\mathrm{CO}_{2}$, supply energy and food security, treat wastewater, combat malnutrition, create jobs and stimulate economic growth [3]. Microalgae cultivation systems could be particularly beneficial in an urban area, where there is an urgent necessity of satisfying the increase in the need for material and energy, while reducing atmospheric pollution and waste generation. Although some authors have been optimistic regarding the sustainability of microalgae biofuels production in outdoor conditions and in their contribution to energy security [10], others have been more skeptical and have emphasized the limits imposed by the entire life cycle of the process [11]. Some authors have shown particular doubt about the economic and the energetic feasibility of this technology, which they have considered to be too expensive compared to other energy sources, with high energy inputs requirements [9]. The existing literature and life cycle assessments (LCAs) have shown contradictory results, which complicate the understanding of the feasibility of the process $[2,12,13]$. However, there is a consensus to deeply explore the real possibilities, especially for marine microalgae in coastal areas [14].

Most studies pay attention to freshwater microalgae $[15,16]$. Marine microalgae have also been described as potential biomass producers [14], and have been targeted as biofuels under different conditions [17-19]. Independent studies have highlighted the importance of considering local coastal resources for biofuel production [7] while exploiting other products that can be used with cultivated biomass [20]. Marine microalgae benefit from freshwater microalgae studies, differing only in some key processes and materials used to produce their biomass [9]. The analysis as a potential resource was therefore also reviewed.

This study aims to show that, despite the economic difficulties of developing this technology on a large-scale, microalgae, particularly marine algae, are a promising biotechnology [21]. However, this is not a comparison of benefits and drawbacks between the two potential sources, as we believe that saltwater microalgae are more suitable in coastal areas with production performances similar to that of freshwater microalgae, considering some differences highlighted throughout the manuscript. We show how microalgae have a great potential to supply energy in a sustainable way that is complementary to other energy sources, and to contribute to the achievement of important SDGs, which is fundamental in an era of environmental, economic and social crisis. We also highlight that, at the moment, there is a need to partially cover a high demand for diesel. Microalgae may thus be strategic, especially in isolated or remote areas where the flow of fossil fuel could decrease in the coming years due to peak oil and an inability to cope with a drastic transition in developing countries. In the first part of the paper, through an extensive literature review, the contribution of microalgae to the achievement of 6 SDGs is analyzed. For each SDG, the numerous advantages of microalgae production are explored, including their contribution to the achievement of important objectives linked to the SDGs such as the reduction of $\mathrm{CO}_{2}$ emissions and poverty eradication. The barriers that limit the development potential 
of microalgae production and their contribution to the achievement of each specific SDG are studied. The SDGs chosen are those in which we consider marine and freshwater microalgae to be a substantial change in current trends, being complementary to other measures. The last section is dedicated to an analysis of the feasibility of an upscaling of microalgae biodiesel production to satisfy the annual energy need of a specific number of households in terms of diesel consumption. We also propose an entirely new and unexpected possibility in which we mix the possibility of having a yield of microalgae for economic purposes coupled with a potential tool to help tropical coral reefs survive the increasing bleaching effects.

\section{Review of Microalgae Contribution to Sustainable Development Goals}

\subsection{Climate Action}

The $\mathrm{CO}_{2}$ level in the atmosphere is increasing drastically and at unprecedented speed, mainly due to human activities and the continuous extraction and combustion of fossil fuels [22]. Since this event is causing the increase in the atmospheric and oceanic temperature with relative negative impacts on the planet, it is in the interest of our society to find a set of solutions to mitigate climate change and stabilize the global mean temperature $[23,24]$ So far, a wide range of physical, chemical and biological technologies have been developed and implemented to sequester and reduce $\mathrm{CO}_{2}$ emissions [25]. Microalgal systems represent a sustainable and attractive opportunity to partially support these targets $[26,27]$. Microalgae are photosynthetic organisms, which need $\mathrm{CO}_{2}$ for their growth, together with sunlight, water, and other nutrients [26]. The advantages compared to other carbon mitigation solutions are that microalgae have a carbon fixation capacity from 10 to 50 times higher than other plants, $100 \%$ of their biomass can be harvested, they can grow on salt and wastewater and do not require fertile land for their growth [3]. Therefore, they do not compete with food production. Their biomass can be subsequently converted into products such as biofuels, human nutrition, cosmetics, pharmaceuticals, animal feeds and fertilizers $[26,28,29]$.

The $\mathrm{CO}_{2}$ sequestration efficiency depends on many factors such as the microalgae species, the culture systems, the $\mathrm{CO}_{2}$ and nutrients provided and the experimental conditions. Table 1 shows the results of several studies concerning the potential of microalgae to sequester $\mathrm{CO}_{2}$. The $\mathrm{CO}_{2}$ fixation rates vary from $0.143 \mathrm{~g} / \mathrm{L} /$ day to $14.5 \mathrm{~g} / \mathrm{L} /$ day. Several microalgae systems have been used to capture flue gas emissions from industrial processes, to purify indoor air quality and to remove carbon from other confined spaces [23,26]. However, microalgae do not allow long-term carbon storage since they decompose rather quickly [25]. To have an impact on the reduction of $\mathrm{CO}_{2}$ level, the biomass should be converted into biofuels that could partly replace current fossil fuels consumption or into co-products that allow to alleviate the economic cost and improve the process sustainability. Thanks to their aeration, organic matter removal and nutrients recycling capacities, microalgae cultivation can also be integrated with wastewater treatment. In this way, energy consumption and $\mathrm{CO}_{2}$ emission of the plants will be reduced [23,25,26,28]. Sayre [29] also suggests the burial of microalgae biomass in geological formations to sequester $\mathrm{CO}_{2}$. However, this method is subject to criticism due to the related risks and the large amounts of inorganic nutrients such as phosphorus and nitrogen that will be buried as well.

Table 1. Microalgae carbon sequestration by specie and production system.

\begin{tabular}{|c|c|c|c|c|c|c|c|}
\hline $\begin{array}{l}\text { Production } \\
\text { System }\end{array}$ & Algae Species & Vol (1) & $\begin{array}{c}\text { Temperature } \\
\left({ }^{\circ} \mathrm{C}\right)\end{array}$ & $\begin{array}{c}\text { Growth Rate } \\
\text { or Biomass } \\
\text { Productivity }\end{array}$ & $\begin{array}{c}\mathrm{CO}_{2} \text { Fixation } \\
\text { Rate } \\
\text { (g/L/day) }\end{array}$ & $\underset{(\%)}{\mathrm{CO}_{2} \text { Supply }}$ & Refs. \\
\hline \multirow{2}{*}{ Open Pond } & Chlorella sp. & 8 & 30 & - & - & - & [30] \\
\hline & $\begin{array}{l}\text { Spirulina } \\
\text { platensis }\end{array}$ & 8 & 30 & - & - & - & [30] \\
\hline
\end{tabular}


Table 1. Cont.

\begin{tabular}{|c|c|c|c|c|c|c|c|}
\hline $\begin{array}{l}\text { Production } \\
\text { System }\end{array}$ & Algae Species & Vol (1) & $\begin{array}{c}\text { Temperature } \\
\left({ }^{\circ} \mathrm{C}\right)\end{array}$ & $\begin{array}{l}\text { Growth Rate } \\
\text { or Biomass } \\
\text { Productivity }\end{array}$ & $\begin{array}{c}\mathrm{CO}_{2} \text { Fixation } \\
\text { Rate } \\
\text { (g/L/day) }\end{array}$ & $\underset{(\%)}{\mathrm{CO}_{2} \text { Supply }}$ & Refs. \\
\hline \multirow{3}{*}{ Photobioreactor } & Dunaniella sp. & - & 27 & $0.17 \mathrm{~g} / \mathrm{L} /$ day & 0.313 & 3 & [31] \\
\hline & Nannochlorophsis & - & 26 & $0.372 \mathrm{~g} / \mathrm{L} /$ day & 0.393 & 15 & [32] \\
\hline & Chlorogleopsis sp. & - & 50 & - & 0.205 & 5 & [33] \\
\hline Airlift reactor & $\begin{array}{c}\text { Aphanothece m. } \\
\text { Nageli }\end{array}$ & 2.4 & 25 & - & 14.5 & 15 & [34] \\
\hline \multirow{7}{*}{$\begin{array}{l}\text { Bubble } \\
\text { column } \\
\text { reactor }\end{array}$} & Aphanothece m. & 3 & 35 & - & 2.621 & - & [35] \\
\hline & Nageli & 1.8 & - & - & 1.45 & - & [36] \\
\hline & Anabaena sp. & - & 27 & - & 1.01 & 10 & [37] \\
\hline & Anabaena sp. & 8 & 25 & - & 0.497 & - & [38] \\
\hline & $\begin{array}{c}\text { Botryococcus } \\
\text { braunii }\end{array}$ & 8 & 25 & - & 0.272 & - & [38] \\
\hline & $\begin{array}{l}\text { Dunaliella } \\
\text { tetriolecta }\end{array}$ & 0.8 & - & - & 17.2 & 15 & [39] \\
\hline & $\begin{array}{l}\text { Chlorella sp. } \\
\text { Chlorella vulgaris }\end{array}$ & - & - & $10 \mathrm{~g} / \mathrm{L}$ & 2.22 & 6 & [40] \\
\hline $\begin{array}{l}\text { Membrane } \\
\text { photobioreac- } \\
\text { tor }\end{array}$ & Chlorella vulgaris & - & - & $0.9 \mathrm{~g} / \mathrm{L}$ & 3.55 & - & [41] \\
\hline $\begin{array}{c}\text { Commercial } \\
\text { scale, } \\
\text { outdoor }\end{array}$ & $\begin{array}{c}\text { Haematococcus } \\
\text { pluvialis }\end{array}$ & - & 20 & $0.076 \mathrm{~g} / \mathrm{L} /$ day & 0.143 & - & [42] \\
\hline $\begin{array}{c}\text { Artificial } \\
\text { wastewater }\end{array}$ & Chlorella vulgaris & - & - & - & 0.624 & 15 & [43] \\
\hline
\end{tabular}

In order to have a positive impact on $\mathrm{CO}_{2}$ reduction, the production of biofuels from microalgae must consume less energy than it can supply, throughout its entire life cycle. The carbon footprint of microalgae biofuels production is an essential element to determine if the production is worthwhile [5,9]. According to the results of a review of LCA studies performed for the cultivation of microalgae for biofuels production, a relevant part (6 over 23) shows negative results regarding the emission of GHGs compared to fossil fuels [12]. However, numerous studies and LCAs state that microalgae are among the most promising technologies for fixing $\mathrm{CO}_{2}$, thanks to their high photosynthetic efficiency which is superior to any other source used to produce energy from biomass [2,28,40,44-46]. In fact, microalgae have the highest net energy yield among the various sources of biofuels and therefore represent a more efficient and sustainable $\mathrm{CO}_{2}$ bio-mitigation strategy [44-47]. In order to have positive effects on $\mathrm{CO}_{2}$ bio-mitigation, it is necessary to improve the power requirement in the cultivation stage [2]. In this sense, the cultivation of marine microalgae in outdoor systems involves a greater reduction of the energy requirements and would allow the upscaling of the cultivation of microalgae biofuels $[9,14]$.

In fact, several processes of the cultivation system such as harvesting and oil extraction represent bottlenecks and need to be improved in terms of both energy consumption and GHGs emissions. For example, the optimization of crucial steps such as lipid extraction is the key to a successful harvesting process [20]. Most of the LCA studies show how nutrients need an essential issue to face in biofuel production and that without the recycling of nutrients such as nitrogen, phosphorus and potassium, the energy and GHG balances are estimated to be negative [12]. Thus, the production of fertilizers requires energy and releases $\mathrm{CO}_{2}$ [5]. $\mathrm{CO}_{2}$ is also essential for the feasibility of microalgae cultivation. It has been shown that the $\mathrm{CO}_{2}$ needed to produce microalgae biomass contributes about 50 percent of the total cost of production. Therefore, if $\mathrm{CO}_{2}$ is not available for free, production will be too expensive. This also represents an opportunity to mitigate air pollution coming from industry 
activity and utilize it to produce biofuels [2]. Regarding the nutrients supply, some research on microalgae biofuels suggests integrating the production with wastewater to supply the necessary nutrients to microalgae $[23,26,28]$, additionally improving the potential use of microalgae for $\mathrm{CO}_{2}$ biomitigation. However, the supply of wastewater implies costs, is not feasible in every location and there are just a few preliminary studies available on this subject $[12,48]$. A better solution to improve the sustainability of the systems resides in the anaerobic digestion and the consequent nutrients and energy recovery from the residues after the extraction of algal oil. This allows the provision of additional fuels such as biogas that could be used to generate electricity on-site $[5,12,49]$. The electricity generated can replace the one used in high-energy processes and that derives from fossil fuels, resulting in a reduction of GHGs emissions. An alternative solution to recycle nutrients is to use cyanobacteria and other bacteria that can biologically fix nitrogen. However, this method requires significant improvement and development that is not yet available [5,50]. Another factor that influences the GHG balance of microalgae biofuel production is the geographic area in which it is produced. In areas where the electricity is generated with alternative energy, the GHG emissions would be lower than in areas producing energy mainly by burning fossil fuels [5]. Not all the areas are suitable for outdoor racer ponds or bioreactors, being the climate features essential for a successful production [10,51]. To improve the microalgae biofuel production efficiency in terms of carbon balance, studies claim for the need for further R\&D related to cultivation technologies and effective algae strain, the necessity to increase the scale of production and the greater accuracy of LCAs studies. Most of the latter are based on laboratory or pilot-scale data instead of large-scale facilities and therefore, a larger number of studies on commercial-scale production is needed to generate more precise results. Furthermore, LCAs are often based on assumptions and limited data and do not consider important processes of the production $[9,12,25]$.

Marine microalgae produce slightly more biofuels than freshwater [52]. They will also be climate change mitigators and we must take the opportunity to understand their potential role in villages or small towns. It has been suggested that marine microalgae can produce enough biofuel to cover the entire planet's (land) transport covering 1.92 million $\mathrm{km}^{2}$ [14]. The same authors also highlight the possibility of creating a very high quantity of edible proteins to be used for example in aquaculture (2.4 GT of protein per year, triple that those produced by soja cultivation). Such numbers may be unrealistic, as we are always aiming for higher productivity, while microalgae will not replace biofuels or global energy demands with $100 \%$ efficiency. However, freshwater, but especially marine microalgae, can be a partial solution (see below) if we consider the possibility of implementing new applications locally. Marine microalgae will utilize a soil extension similar to that of freshwater microorganisms and, if properly stimulated $[53,54]$, oil production can be as high as that of freshwater. A major problem will be plant corrosion which must be considered in the overall production and process activities [9]. However, the increased amount of nutrients and micronutrients associated with marine water can offset such long-term investment [55].

In summary, many improvements are required to make marine microalgae cultivation more sustainable and to increase the potential to reduce GHGs levels in the atmosphere. However, microalgae carbon sequestration and biofuel production are promising and sustainable methods to help toward facing the issues related to global warming, and have many advantages compared to fossil fuels and other conventional biofuel sources such as terrestrial plants $[12,14,44]$. Further research in anaerobic digestion for biogas production and nutrient recovery, upscale in the production systems, more efficient technologies and more accurate LCAs suggest the possibility to develop this technology and to make it more economically and environmentally sustainable [50]. 


\subsection{Clean Water and Sanitation}

SDG number 6 aims to ensure the availability and sustainable management of water and sanitation. Microalgae are a promising tool, which can contribute to achieving this objective [51,56,57].

In fact, despite the growing recognition of the great importance of freshwater and more sustainable management of the latter, there are still risks concerning water availability and quality in many parts of the world [22]. In 2015 almost one-third of the world lacked safe drinking water supply and about $60 \%$ were not provided with safely managed sanitation services [23]. Regarding sanitation, the primary and secondary treatment processes have been implemented in many areas of the world enabling the removal of suspended and floating materials and organic materials. However, the effluent resulting from these two processes is loaded with inorganic nitrogen and phosphorus that could cause eutrophication and problems related to the presence of refractory organics and heavy metals [51].

As stated by several studies, marine and freshwater microalgae culture could provide a remediation role to wastewater treatment as microalgae have the potential to remove inorganic nitrogen and phosphorus that they need for their growth $[38,51,57,58]$. Thanks to their ability to remove heavy metals and some toxic organic compounds, they help to reduce the secondary contamination of water $[20,46]$. Therefore, microalgae can contribute to tertiary and quaternary wastewater treatment, allowing a potential offset of the economic costs and an improvement in the environmental balance and the carbon footprint of the treatment plants $[51,59,60]$. The wastewater treatment by microalgae represents an interesting opportunity especially for least developed countries, where the quality of water is low, and the improvement requires high and often unaffordable investment costs. Thus, in many developing countries only cheap and basic wastewater treatment processes have the chance to be implemented. Microalgae cultivation could improve the quality of the water at a lower price compared to existing and conventional technologies and tertiary treatment systems $[57,61]$. However, it must be considered that large volumes of water to be treated can overwhelm the capacity of the microalgae. In the case of marine microalgae, their use for these purposes is probably more limited since most of the wastewater comes from freshwater and sewage uses.

Figure 1 shows the integration of microalgae cultivation with wastewater treatment. The integration of microalgae cultivation with wastewater treatment represents a win-win situation, since as mentioned above, microalgae also need some of the nutrients contained in wastewater for their growth and the provision of these nutrients is often the most energy and carbon-intense process that limits the feasibility of a sustainable microalgae biofuels production. In the case of marine microalgae, this implementation is much more complex, although the possibility of mixing salt and freshwater can be considered to enhance biofuel production.

Furthermore, other challenges related to microalgae cultivation such as land and water availability would be partly resolved [43,61].At the same time, thanks to the removal of nutrients and the recovery of $\mathrm{CO}_{2}$ and heat, it would be possible to achieve the target of optimization of the energy consumption and carbon footprint of wastewater treatment plants, while producing renewable energy as well.. Thus, microalgae would replace some processes traditionally performed by the treatment plants and possibly generate energy from the algal biomass residues that could be used in situ, additionally to the production of biofuels [56]. However, microalgae biofuels production from wastewater has a limit, as wastewater does not always contain the necessary nutrients needed for the growth of microalgae $[5,61]$. The nutrient concentration in wastewater depends on the geographical and urban areas and the source of wastewater (urban, industrial or agricultural). Chisti [5] claims that at best, microalgae can respond to $1 \%$ of the fuel demand of a large city in the United States. This is a great amount considering that microalgae are not the solution but a part of it, and although to a small extent, they can contribute to a country's energy security. 


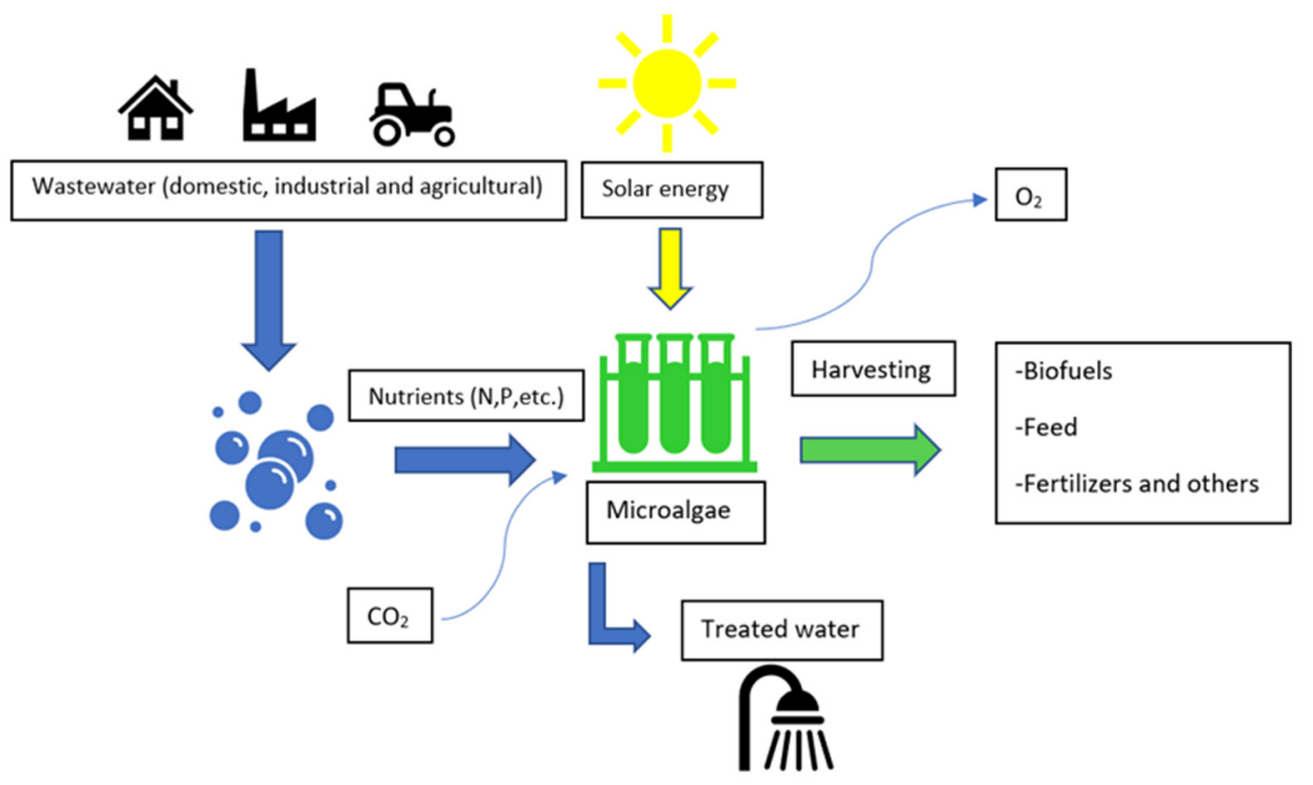

Figure 1. The production of biofuels from microalgae can be combined with the treatment of wastewater from different sources. Thanks to the ability of microalgae to remove pollutants from wastewater, the latter can be reused for different purposes such as agriculture. Likewise, microalgae find nutrients such as phosphorus and nitrogen necessary for their growth and therefore to produce biofuels and other products. Treated water (with low nutrient load) will be thus available for the citizen.

Several technical challenges have been identified in the integration of microalgae biofuel production and wastewater treatment [50]. The culture conditions such as nutrients concentration, temperature and light strongly influence the removal efficiency of microalgae and therefore a little deviation in the parameters could lead to inefficient nutrient removal and algal growth rate. For instance, it is necessary to continuously measure the wastewater chemical composition to allow optimal growth and nutrients removal rate. Quantities of phosphorus and nitrogen should not be excessive, and should be lower than a certain amount to achieve optimal conditions. The same is true for temperature and light [56]. It is also important that a match between the treatment capacity of the cultivation system and the targeted wastewater to treat is realized. Not least, there is the necessity to prove that microalgae wastewater treatment is economically and environmentally favorable compared to other existing technologies or to better define where the investments must be made to improve its feasibility. Otherwise, the implementation, development and upscale of this technology will be difficult $[56,58]$. The harvesting process is also identified as a bottleneck, as considerable amounts of energy are required. Immobilized living cells help to retain the algal biomass and the harvesting before the discharge of treated water is not required, allowing to save energy. However, this technology is more expensive compared to traditional ones, making biodiesel production unlikely [56]. A better option is provided by the microalgae consortia with other bacteria which presents the same advantages of immobilized living cells but at a lower cost. Additionally, this present also benefits compared to monoculture in terms of higher algal growth rate, nutrients uptake, and resistance to environmental conditions oscillations [56].

To overcome the limits related with the integration of microalgae biofuel production with wastewater treatment and to allow implementation at a larger scale, future studies should focus on the optimization of microalgae culture, selection of appropriate nutrients contents in wastewaters, efficient harvesting technics and on the improvement of nutrient removal and algae growth rates. In this sense, the microalgae culture should be studied under extreme environmental conditions and microbial interaction with improved analysis of the related advantages, ecology, engineering and cultivation conditions [56,59]. 
In summary, the 'symbiosis' between microalgae cultivation and wastewater treatment offers advantages and helps to overcome challenges for both systems. It allows reducing the capital costs, solving problems related to scalability and developing and optimizing the microalgae cultivation and biofuel production at a commercial scale [58]. The feasibility of this technology would improve the supply of clean water and sanitation, reducing costs and increasing the sustainability of the process, while allowing additional renewable energy production and the replacement of fossil fuel. By doing so, it will be possible to achieve two urgent sustainable goals at the same time, to which countries around the world are already struggling. Furthermore, in the least developed countries, this kind of approach will definitively help to face the transition between fossil fuels and other energy sources, considering the difficult task of the elimination of all the diesel and ethanol engines.

Despite the recent improvements and developments in coupling biofuel production and wastewater treatment, many of the available studies on the production of biofuels from microalgae grown in wastewater are limited to the laboratory scale, which is preventing the scalability of the technology. Further research and innovation in the areas discussed above are required to allow the scalability and to improve the cost-effectiveness and sustainability of microalgae biofuels production using wastewater $[60,61]$.

\subsection{Zero Hunger}

The second SDG aims to reduce hunger around the world, achieve food security, improve nutrition and promote sustainable agriculture. As the world population is expected to increase in the next decades, the food demand and the portion of undernourished people around the world will follow the same patterns. Responding to this demand and achieving the target set by SDG number 2 will be a challenging task for the years to come.

The energy sector is competing with the arable land, nutrients (especially phosphorus) and water available to produce food and feed, particularly the first-generation biofuels that derive from crops such as soy, maize, and palm, which require a considerable amount of land and water for their production [29]. The growing demand for crops for biofuels production by industries is proved to be one of the main factors causing the increase in the food prices around the globe. Higher food prices particularly affect countries in subSaharan Africa, where the population is highly dependent on importations for their food provision [62]. The second-generation biofuels present some advantages as they do not compete directly with arable land, but they also do not represent a suitable alternative [45]. Thus, their production could have consequences on land-use change and they have low conversion rates that compromise the potential to contribute to energy security and increase the requirement of land for the production [62] (Figure 2).

Attention and interest have been growing regarding the development of third-generation biofuels from microalgae compared to first and second-generation biofuels, because of their higher productivity per unit area, the capability of growing in non-arable land and therefore for their non-competition with fertile land for food production $[3,25]$. Since microalgae cultivation systems such as ponds and bioreactors can be placed in non-arable or abandoned land, they can be the best options to supply oil demand around the globe, while not competing with the production of food $[25,29,62]$. Thus, microalgae biofuel production can have positive impacts on food security if algal biomass in used to substitute corn and soybean and to derive coproducts such as food additives for humans, livestock feeds, aquaculture feed and fertilizers that have the potential to reduce food price volatility. In the case of marine microalgae, the water footprint is also a factor to consider. While freshwater microalgae need $3726 \mathrm{~kg}$ freshwater $/ \mathrm{kg}$ biodiesel, marine microalgae (because of evaporation in open race ponds) only need 3,993,726 kg freshwater $/ \mathrm{kg}$ biodiesel [27]. Marine microalgae also use micronutrients already dissolved in the water mass more efficiently that freshwater algae [14], so their biomass production may be slightly higher. All these factors must be considered when applying a new energy model based on microalgae, especially those coming from the marine environment. However, precise estimations 
of the contribution to food security are not possible until microalgae biofuels are not commercialized at a medium-large scale [63].
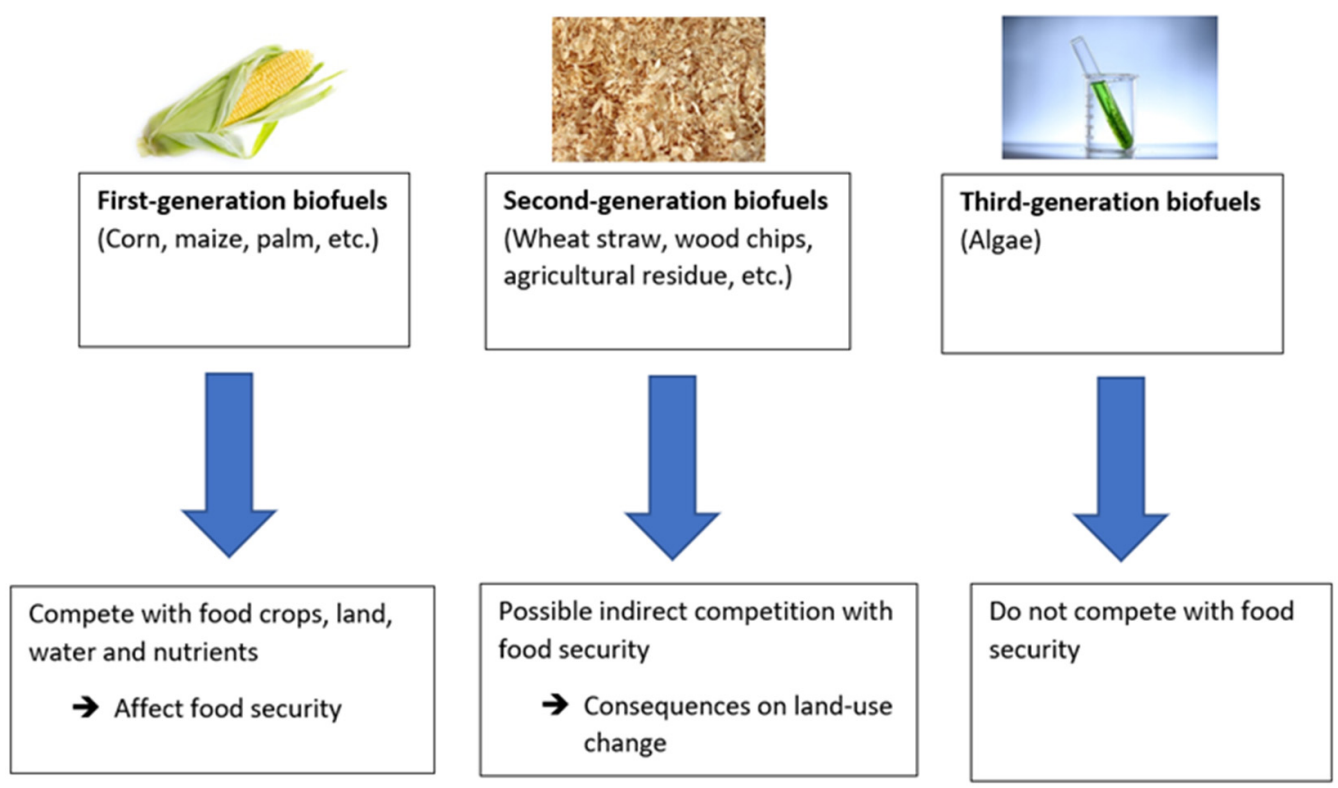

Figure 2. Different impacts of biofuel sources on food security and land-use change.

Microalgae such as Spirulina and Chlorella (a model that has different characteristics suitable for comparison with marine microalgae) are used as dietary supplements to support human health as they are rich in several nutrients that are essentials for human alimentation. They are rich in vitamins, lipids, minerals, and proteins that can be easily absorbed by humans and contribute to keeping essential functions of the body. Spirulina was declared as one of the greatest foods for the future by the United Nations World Food Conference of 1974 and the recognition of its contribution to combat hunger and malnutrition and to provide high-quality food is growing [64]. Several organizations and associations are developing knowledge about the benefits of microalgae regarding alimentation and are helping some developing countries to grow microalgae for their nutrition. For instance, Antenna, which is a Swiss foundation is working for the distribution and the local production of Spirulina to improve the nutrition of poor communities and ameliorate the state of malnourished children. Thanks to its nutritional and therapeutic proprieties and the potential to be cultivated locally, Spirulina also provides an efficient approach for the nutritional care of people affected by HIV in Africa, and it can be complementarily used with other strategies combating malnutrition such as dietary advice and awareness-raising. It can be easily grown locally and presents several benefits in terms of effectiveness, local sustainability, autonomy, yields and water needs [65].

Growing Spirulina, or other similar microalgae, locally with the purpose of combating malnutrition allows the communities to create additional revenue streams, to enforce local initiatives, to meet their own food needs with local resources and to reduce their dependence on external aids [65]. Marine microalgae have very similar nutritional possibilities, being less explored but also an excellent nutritional source, combined with the possibility of capturing $\mathrm{CO}_{2}$ from the atmosphere [7].

\subsection{No Poverty}

SDG number 1 proposes to eradicate poverty in all its forms and everywhere by 2030 . Even if extreme poverty has declined significantly in the last decades, the latest global estimates show that $11 \%$ of the world population (about 783 million people) were still living below the extreme poverty threshold in 2013 [22]. Microalgae biofuel production can contribute to social well-being through net job creation, providing part of the needed energy 
to role several engines. Thus, some microalgae industries already have a reported number of employment opportunities and they can benefit from government support. In addition to direct employment opportunities, indirect employment is generated for suppliers of materials and resources necessary for microalgae biofuel production [63]. Expanding the activities of growing microalgae in developing countries to derive and sell products may be a strategy that could help to eradicate poverty by creating local jobs and generating new sources of income for the population.

In developing countries, open ponds cultivation offers the best solution in this sense, because it is associated with lower requirements regarding energy, initial investments, technical skills and maintenance [59]. Additionally, the climate of several developing countries in South Asia and Africa is favorable for the cultivation of microalgae thanks to the highs level of sunlight and temperature during the whole year. However, the high rates of evaporation in tropical countries would increase the water demands of the systems and compete with water supply for other use [62], except in the case of marine microalgae use. Maximum oil productivity (24-27 $\mathrm{m}^{3}$ Oil/ha/year or 13-15 g oil $\mathrm{m}^{2} /$ day) can be obtained in countries such as Brazil, Colombia, Egypt or Mozambique [52], considering the climatology and not too complicated harvesting options. Oil production and the promotion of biofuel can help local communities to be independent of main distributors, taking biogeographic differences into account. Thus, in tropical areas such as Kisumu (Kenya) a non-negligible production can be stimulated $\left(2.28 \mathrm{~g}\right.$ oil $/ \mathrm{m}^{2} /$ day), while in Punta Arenas (Chile) production can be diminished by light and temperature conditions $\left(0.77 \mathrm{~g}\right.$ oil $/ \mathrm{m}^{2} /$ day) [52]. In a country such as Brazil, $16 \%$ of non-arable land could be used to produce biofuels from marine microalgae suitable for land transport [52], as well as partially supplying demand for bioenergy (along with other strategic renewable energy policies).

In terms of economic benefits, the production of microalgae biofuels does not allow yet to contribute to large-scale economic growth and poverty eradication in developing countries [62]. Chisti [5] argues that once the problems related to water, carbon dioxide, and fertilizers are solved, algal biofuels would be competitively produced compared to petroleum. Biodiesel cannot compete with the prices of fossil fuels yet as its production results too expansive [5]. The integration of other high-value products from microalgae such as food, feed, fertilizers, pharmaceuticals, and cosmetics could help to overcome the economic unfeasibility of biofuels from microalgae $[23,28]$. However, nowadays the concept of biorefinery is an available option just for more developed countries, while it struggles to be implemented by low-income countries around the world [62]. Thus, to implement and develop the production of biodiesel and other co-products, relatively high economic, technical, educational and political expertise that is not found in some developing countries is necessary. Continents such as Africa and South America have a small percentage in the contribution to the world's publications about algae biofuels, which is demonstrative of how they are struggling in developing human capital around this technology [62]. Another issue regarding biofuel production in developing countries and poverty eradication is to make sure that the benefits deriving from the production of biofuel allow the communities to improve their incomes and to overcome extreme poverty. It is possible that a great part of the benefits will go into the hands of private companies and other people of interest, instead of being allocated among the local communities. Stronger participation of the full range of stakeholders surrounding the technology is essential to enable better justice and equality.

While it is not sure if microalgae biofuel production will contribute to reducing poverty in developing countries, fewer uncertainties exist about other utilizations of microalgae cultivation that do not require high technological levels or the involvement of large international companies. As discussed above, the farms which are involved in the cultivation and distribution of Spirulina, help to combat malnutrition, create job positions and new revenue streams for the local communities [65]. At the same time, this creates domestic investments and local supplies that reduce the reliance on the import of 
international dietary products. In this sense, the transfer of technology and knowledge regarding local production of microalgae, together with awareness-raising, offers a great opportunity to deal with malnutrition and poverty in continents such as Africa [65].

The production of Spirulina results are more interesting compared to other species that could be cultivated in low-income countries and that can create employment and income opportunities as well, thanks to its unique benefits, but other possibilities are open and require little change to be feasible. The ability to grow in wastewater, the high yields, the little requirements of space and water, the facility of cultivation and distribution, the effectiveness to cure malnutrition thank to the high nutrients content, the fact that it can be grown locally and sustainably and that it can provide small activities for women, are some of them [65]. However, the possibility of using marine microalgae is an open question, as its feasibility has been demonstrated but not its possibilities for upscaling yet [66]. What we should do is apply a different perspective, where local needs and small to medium scale applications outweigh the economic advantage per se (upscaling to transform marine or freshwater microalgae cultivation into an export element).

\subsection{Sustainable Cities and Communities}

Microalgae cultivation systems can be particularly beneficial in urban areas, where the urgent necessity of satisfying the increasing need for material and energy is challenging the reduction of atmospheric pollution and waste generation. The built environment is estimated to contribute from 40 to $50 \%$ to the global GHGs emission through fossil fuel consumption and therefore the reduction of the atmospheric pollution in cities has a great potential for the mitigation of global warming [67]. While up to date efforts in improving the environmental sustainability in urban areas has focused on solutions such as photovoltaics, wind turbines and geothermal, microalgae cultivation systems and their integration into urban spaces are receiving growing interest [67]. Microalgae can play a crucial role in helping urban areas to reduce GHGs emissions, increase energy efficiency and to partially substitute fossil fuel consumption [67-69].

A wide range of researchers are investigating new efficient ways to introduce microalgae into cities and buildings. Photobioreactors can be integrated into buildings in the form of facades [69]. This allows having mutual benefits for both the microalgae cultivation system and the building. Microalgae can absorb $\mathrm{CO}_{2}$ that is present in flue gases emitted from the building and use it for their growth. The nutrient demand for the production is therefore reduced. The building is providing an illuminated surface, which is necessary for the growth of microalgae and, thanks to thermal regulation, the energy consumption of both the building and the microalgae system will be reduced [69]. For instance, the photobioreactors can filter the sunlight that irradiates the building during summer and provide it with thermal energy in excess from the cultivation during winter months, enabling to save energy for cooling and heating the building. The thermic conditions of the building during the different seasons could also be used to regulate the photobioreactor temperature [69]. In addition to $\mathrm{CO}_{2}$ feeding and thermal regulation, integrating the photobioreactors into the building also helps to reduce the operational costs, as amortized in the constructive function. In Scandinavian countries the use of wastewater, waste heat and waste $\mathrm{CO}_{2}$ has been proposed to grow marine and freshwater microalgae [18], using some of the geothermal energy to stabilize the temperature in bioreactors or razer ponds. Thanks to the ability of microalgae to grow in wastewater and to obtain nutrients from it, the grey or black water of the building could be used to address the water and nutrients needs of the photobioreactor from buildings or condominiums of small houses. In this way, the recycling of water and nutrients improves the economic and energy performance of the photobioreactor and the treated water could be reused by the building. However, the challenges related to microalgae cultivation in wastewater discussed previously must be considered.

Indeed, a careful LCA is needed to improve the real possibilities of such cultures, even on a small-scale applications. Outdoor conditions have proven much more beneficial in 
marine microalgae $[9,66]$, as the energy expended is significantly less (light and temperature) and the facilities are much easier to build and maintain [70]. If the aim is to feed small or medium-sized cities, the possibility of creating bioreactors and/or racer ponds is much more realistic than on a large-scale [71]. Promoting microalgae cultivation to increase the partial energy independence of a certain areas will depend on a good analysis of the materials, energy and logistics used, combining bibliographical data, industrial needs and an accurate local study of the socio-economic structure of the implementation area [11,55]. Studying the marine microalgae cultivation with different approaches (cost of $\mathrm{CO}_{2}$, energy investment, use of material, economic benefits) will therefore be essential [70], but a nonlinear economic benefit could perhaps help to realize this option for future generations. Since energy is a very strategic issue, attention should be paid to local benefits rather than purely monetary income from the productivity.

Aside from the direct benefits of the integration of microalgae cultivation systems into the built environment, the microalgae biomass can be harvested to derive biofuel and biogas to provide the building with electricity and heat. This offers additional potential to produce sustainable energy and to reduce the environmental footprint of the buildings. Other important benefits related to the integration of microalgae into the built environment are that it reduces the need for surface to cultivate and therefore the competition with land for other aims and it covers important aesthetic and iconic values. Strong educational values are also covered, as it could be a crucial element to increase the environmental awareness of the population and to show the ecological orientation of the city and the companies.

Nowadays the only existing building that integrates photobioreactor facades to produce biofuels and biogas to cover entirely the energy demand of the building is the Bio-Intelligent Quotient (BIQ) in Hamburg, Germany. This infrastructure includes a $\mathrm{CO}_{2}$ and nutrient supply, temperature control, biomass filtering and harvesting, monitoring and controlling, harvesting, storing and distribution of the heat and microalgae biomass transportation to an energy management center to be converted into biofuel and biogas [68]. The excess heat from the photobioreactors is used to heat domestic water, warm the interiors of the buildings or is stored in an aquifer under the building [67]. In addition to this real algae-powered building, other projects exist that are trying to design new and innovative ways to integrate algae into buildings. Most of them use several types of photobioreactors and take water and $\mathrm{CO}_{2}$ directly from the building or nearby infrastructures. Although their high innovative and ecological frame, these projects are only theoretical and therefore their feasibility is not measurable yet.

Microalgae integration into urban areas does not occur exclusively through buildings, but also through their introduction into urban canopies, pavements, fountains, parks and public and private spaces that produce large amounts of $\mathrm{CO}_{2}$. This represents an innovative and emerging way to increase the sustainability of cities and to develop the utilization of microalgae technology.

Despite the great contribution that microalgae can bring to an urban area, there are notable limits that must be considered. The issues are related to the environmental, technological, regulatory and political, economic and social aspects surrounding the technology [67]. Regarding the photobioreactor integration in building facades, the technical challenges are to respond to the architecture requirements, optimize the light capture, improve the maintenance issues and design efficient system and materials to avoid biomass fouling on the glazing panels [69]. From the environmental point of view, it is essential to prove negatives or at least neutrals $\mathrm{CO}_{2}$ emissions of the technology during the entire life cycle [67]. Competing renewables sources that can produce more energy and potential contamination represent other limits to the expansion of microalgae integration in urban areas. Another substantial barrier is that the economic cost of the photobioreactor facade is much higher compared to conventional facades and moreover it implies maintenance, construction, operational and risk management costs as well [67]. Until this technology will not be adopted by other buildings, it is difficult to make a realistic conclusion about the cost, payback period and economic feasibility. Pruvost et al. [69] argue that the improvement 
of $\mathrm{CO}_{2}$ feeding and the thermal regulation between the two systems is essential to reduce the operational cost. To reduce the costs, it is also essential that the technology produces a positive energy balance and, therefore, it allows to save energy. In Pruvost et al. [69], the energy balance of a facade-integrated photobioreactor results to be negative and therefore not suitable for biofuel production. However, small-scale production of microalgae biofuel with positive energy balance has been realized and moreover, their integration into buildings cover important aspects beyond the economic one [12]. If in a near future the economic priorities change (i.e., the use of biofuels is considered a strategic issue in local, regional or national policies to be more self-sufficient in front of fossil fuels), the conception of benefits may change drastically.

In this equation we must add the problems of harvesting and oil extraction, which must be carefully considered as potential drawbacks. The selection of the harvesting method depends on marine or freshwater microalgae [72], making the sale of biofuel uncompetitive compared to the supply of fossil fuel [73]. It was proposed to look for the best strains of microalgae in order to minimize costs, as the price of biofuels derived from microorganisms is not yet very competitive. High growth rates and high lipid content is the ideal combination [74]. However, it should be emphasized that not only the economic advantages have to be considered, but also the potential socio-ecological features on small and medium-scale production. As LCAs studies on small-scale microalgae biofuel production have demonstrated the potential for positive energy outcomes [12], integrating microalgae in cities is far from being unachievable. Despite the economic unfeasibility, the integration of microalgae into the built environment offers numerous advantages in terms of the environment, energy efficiency and ethics that should be an interest of urban areas. Further research offers a great opportunity to explore the potential and to expand this technology.

A series of political and regulatory issues also concerns the implementation of this technology. Thus, in countries where the political power and influence of coal companies are strong, it can be more difficult to implement alternative energy sources such as biofuels from microalgae. Furthermore, this new technology would also imply compliance with the building code and a series of guidelines on health and safety laws relating to operators and occupants of buildings. The requirements for technology certification and its installation could be raised by bodies such as health and safety professionals or energy and water departments of the cities concerned. Finally, social barriers such as the negative perception of microalgae from any stakeholders (e.g., occupants, citizens and industries) should be considered. Microalgae could be associated with odors and potential health impacts [67]. The social acceptability of microalgae biofuels should be measured with indicators such as public opinion, transparency, effective stakeholder participation and risk of catastrophe [63].

In summary, the studies state that microalgae introduction in urban areas represents an opportunity to create mutual benefits for both systems. Microalgae can provide biological benefits to the cities such as $\mathrm{CO}_{2}$ absorption, production of oxygen, recycling of nutrients, wastewater treatment, energy-saving, shade, and insulation while enabling the production of biofuels and other value-added products. The integration allows the biofuel production to find the cultivation surface and the supply of nutrients, which are factors that would otherwise have reduced the overall sustainability of the production process. At the same time microalgae, introduction in urban context covers educational, aesthetic and ethical features as well.

\subsection{Affordable and Clean Energy}

The population growth and the increasing energy demand risk to challenge the availability and supply of energy and can lead to an energy crisis. The development of new renewable energy is an essential challenge for the years to come, to meet both the growing energy needs and the urgent need to find alternative and more sustainable energy sources. 
It is not clear yet If microalgae derived biofuels have the potential to partially replace the current diesel consumption and contribute to energy security, especially at a large scale. The results of the existing literature are often conflicting, and there is no clear consensus about the future evolution of the microalgae biofuel market and the potential of commercialization $[12,13]$. The factors that influence the results regarding the feasibility of energy supply by microalgae biofuels are many and depend on the case of study. The results can differ depending on the methodology, the algal strain, the boundaries, the functional units, the geographic conditions and the reference system that the authors are considering in their studies. This is not surprising, because different research groups use different microalgae, and when a study is made in outdoor conditions, the seasonality, light-harvesting, and dependence on environmental factors by the phytoplankton may vary widely. The studies performing the LCA for microalgae biofuels production are not numerous and have been performed mainly between 2009 and 2012. These are based on laboratory or pilot scale because large-scale commercial production of microalgae fuel does not exist so far [68]. Therefore, the existing LCA studies are limited and based on strong assumptions, which lead to uncertainties and limit the understanding of the sustainability of the process. Many studies are constrained to literature or industrial numbers to make calculations [21], the upscaled experimental part being scarce. Great part of the LCA studies still shows negative results concerning the energy balance and concludes that biofuel production from microalgae is an energy-intensive process [9]. For example, both harvesting and dewatering have been identified as the most problematic in terms of energy and monetary costs (20-30\% of the production [21]), but some studies use indirect methods (indicators) to calculate these costs. In general, the key energy-intensive hotspots identified are nutrients source, photobioreactor design, lipid extraction and dewatering and drying of biomass $[2,12,13]$, and the difference between studies is sometimes substantial. The biogas produced from microalgal biomass has different approaches that have several advantages and drawbacks, being the choice of the method directly related to the economic, logistic and species-specific possibilities [50]. The strategies proposed to improve the energy ratio of the process are the recycling of nutrients, engineering of oil extraction to reduce fossil energy inputs, hydrothermal liquefaction of whole biomass, flocculationsedimentation with centrifugation for biomass recovery, bacteria consortia, anaerobic digestion and diversification of the biodiesel production from microalgae with other energy outputs $[5,20]$. However, further research and development are needed to test the potential to improve the energy balance of biofuel production. Additionally, the authors claim for a more accurate and harmonized approach to investigate the industry of algae biofuels and for a common agreement on how to conduct an LCA [13]. This would help to achieve more convergent results between the range of LCAs performed and therefore to increase the comprehension of the feasibility of this technology.

Despite the negative trend concerning the results on the energy balance of microalgae biofuels production, still, some positive result and a great number of proposed improvements exist. Combined with further research, these have the potential to ameliorate the energy performance of the process at each stage. As we will suggest later, the scale of the application will also matter. The idea of creating bioreactors to power large cities is probably not the best way to optimize this kind of energy production. Some authors proved that third-generation biofuels from microalgae are performing better than second-generation biofuels, and the steps to reach significant positive applications are closer $[2,44,45]$. Other sources of terrestrial biodiesel (rapeseed and other oil plants) have proved useful but not as efficient as microalgae, as their production is low compared to marine or freshwater microalgae [75]. In the next decade, the use of these microorganisms must be considered as a good complement to other renewable energies, replacing terrestrial plants that need arable land and can interfere with food sovereignty in many areas [3].

Finally, it is to be pointed out again that while measuring the sustainability of the process, most studies focus on energy and carbon balances, while other important factors are overlooked. The impacts on water, biodiversity, local employment, and food secu- 
rity should also be considered while assessing the feasibility of microalgae biofuels [64]. Efroymson et al. [63] pointed out that in addition to environmental indicators, a set of socioeconomic indicators should be used in this sense, to improve the sustainability of algal biofuels. Thus, categories of indicators that have not yet been measured by the published assessments of commercial microalgae-based biofuels include social well-being, energy security, external trade, profitability, resource conservation and social acceptability [63]. Only a few studies have been published on the importance of socio-economic indicators in measuring the sustainability of the production of biofuels based on microalgae. The next session draws an analysis of the potential contribution of microalgae biofuels to energy security.

\section{Microalgae Potential for Energy Security}

\subsection{An Example of Biodiesel Small-Mediuma Large-Scale Production with Microalgae}

Energy security is intended as national security in terms of the availability of natural resources for energy consumption. Microalgae-based biofuels offer a great opportunity in this sense, as they provide additional diversification, independence, and continuity in the energy supply [63]. Although it is not possible to precisely estimate the projection of algal biofuels in the future and their contribution to fuel supply before commercialization, it can be stated that they can contribute to stabilizing the price volatility of fuels, especially in areas that are highly dependent on oil imports [63]. Another sector that will benefit of microalgae biofuels development is aviation. Thus, since the aviation sector mostly requires liquid fuels, not many other energy sources have the potential to create a local supply. Furthermore, the supply of petroleum presents disadvantages in terms of political instability, fluctuating prices, and inefficient transport due to the distance. However, microalgae biofuels production is also subject to risks such as ponds crashes and extreme weather events that could affect the supply [63].

To study the potential contribution of microalgae biodiesel to energy supply, part of this study was dedicated to analyzing and comparing the efficiency of microalgae biodiesel production with the consumption of biodiesel at different household levels. The main objective here is to analyze how microalgae allow an energy transition from fossil fuels to biofuels, in terms of surface and water requirements. The calculation is based on the one hand on diesel consumption data for households in a temperate area and on diesel consumption for cars, and on the other on data about microalgae biodiesel productivity obtained from two studies that found both positives net energy ratios and GHGs balances.

The first study considered is from Batan et al. [46]. The authors performed an LCA for the cultivation of the species Nannochloropsis in a photobioreactor system to compare the production of microalgae biodiesel to petroleum diesel and other biodiesel sources. The LCA boundaries go from the growth stage of microalgae until the distribution of biodiesel to pumping stations [46]. The system is supposed to be in a temperate area of the United States. The net energy ratio (NER) of microalgae biodiesel production is 1.08 MJ of energy produced per MJ of energy consumed. Considering the $\mathrm{CO}_{2}$ sequestered during microalgae growth and the $\mathrm{CO}_{2}$ emissions during the entire process, the net lifecycle GHGs emissions of microalgae biodiesel shows that $75 \mathrm{~g}$ of $\mathrm{CO}_{2}$-equivalent emissions are avoided every MJ of energy produced [46]. Considering biodiesel to energy conversion of $33 \mathrm{MJ} / \mathrm{L}$, the extracted oil yield is about 43,009 L/ha/year (1419 GJ/ha/year). Once the energy inputs needed to produce this amount of biodiesel are considered, the derived net energy yield from Batan et al. [46] is about $100 \mathrm{GJ} / \mathrm{ha} /$ year. The second study is from Stephenson et al. [11], which carries out an LCA of microalgae biodiesel production in the United Kingdom for both raceways and air-lift tubular bioreactors. The study shows potential lipid productivity of about 40 tons/ha/year of oil for the species Chlorella vulgaris. It also shows that cultivation in typical raceways is more environmentally sustainable than fossil-derived diesel and other types of bioenergy. However, cultivation into air-lift tubular bioreactors presents higher energy requirement and $\mathrm{CO}_{2}$-equivalent emissions than petroleum diesel [11]. The NER related to the cultivation of microalgae in typical 
raceways is $1.46 \mathrm{MJ}$ produced per MJ consumed [2]. Therefore, considering the previous biodiesel energy conversion of $33 \mathrm{MJ} / \mathrm{L}$ and a diesel weight of $0.85 \mathrm{Kg} / \mathrm{L}$, the estimated total energy yield of microalgae biodiesel production in raceways is about $1553 \mathrm{GJ} / \mathrm{ha}$ /year and the net energy yield is $490 \mathrm{GJ} / \mathrm{ha} /$ year.

Concerning the amount of diesel needed by households, an annual household diesel consumption of circa $115 \mathrm{GJ}$ is estimated [76,77]. It is necessary to consider that these data are subject to approximations and that the factors that influence the liters of diesel consumed per car and per home are many and can vary between different types of households, areas, and consumers. These numbers suggest that a small to medium scale production is possible and could have complementary benefits for rural societies. The independence of biofuel production, once optimized, can be the key to allowing people to control part of their energy supply. We do not foresee large-scale productivity of biofuels capable of powering large or very large cities as the problems of logistic, materials, and land use will be overwhelming. However, using this energy on a small to medium scale will certainly be an alternative to consider.

\subsection{Apply Symbiodinium Biodiesel Production to Save Coral Reefs?}

We must think "out of the box" if we want to be successful in our future energy management. We have shown that there are possibilities in the application of marine microalgae as an alternative for biofuel production, being other previous works supporting this idea $[7,8,27]$. Biofuel production can partially cover the needs of an impending oil crisis, providing a renewable resource ready to be used [7], but we must consider the variability of the ecozone and the constraints of each region. The production of oil or gas from microalgae is far from entirely replacing global energy needs, but it can guarantee self-sufficiency, especially in remote areas or in small villages where there will be more difficulties to provide fossil fuels in the near future. Coastal tropical and subtropical areas are the most valuable for producing oil from marine microalgae [52]. Moreover, many of these places are isolated and at risk when an energy crisis reduces the availability of fuel. Biofuels produced from marine microalgae may have other unexpected uses, compatible with energy demands and which also directly cover ecological problems [78].

We are now starting to understand the importance of the Marine Animal Forests (MAFs) as carbon immobilizers [78]. MAFs are eco-engineered based habitats in which animals (metazoans such as corals, gorgonians or sponges) are dominant [79]. MAFs are perhaps the largest biome in the world, being dominating from $50 \mathrm{~m}$ depth to the bathyal benthic areas around planet [80]. Among these habitats, coral reefs can be one of the most important carbon immobilizers, being also a biodiversity hotspot and a pool of ecosystem services [78]. Coral reefs are now ongoing profound transformations due to climate change, with bleaching being one of the main impacts devastating these important ecosystems $[81,82]$. Restoration plans are now envisaged as a potential solution to recover the essential set of ecosystem services offered by these MAFs $[78,83]$. Future plans for Coral reef restoration could immobilize a large amount of carbon in their three-dimensional structures, so we can propose ideas where the combination of biology, sociology and economics provide a balanced landscape that can even be challenging for local economies [84]. The biological approach in which the coral community is saved through an efficient coral replanting plan with Symbiodinaceae, which is well adapted to temperature changes [85], may be not sufficient to realize carbon storage plans. We have to mix models and needs. In this context, the evolution in the laboratory of cultured Symbiodinium (the main dinoflagellate responsible for the photosynthetic transfer of organic matter to the coral) under high temperature and $\mathrm{pCO}_{2}$ selection, followed by inoculation in coral hosts with evolved algal cultures may works $[85,86]$. However, a pool of these algae must be viable to replant the microalgae after the bleaching event. The Symbiodinium (microalgae) biomass required for inoculation in corals may come from outdoor bioreactors [53] that will continuously produce biofuel under optimized conditions $[9,10]$ (Figure 3). A slight change in $\mathrm{N}$ or temperature conditions can increase the productivity of an already lipid-rich microalgae 
(approximately $38 \%$ of dry mass [87]). These marine microalgal cultivations can bring a huge amount of biodiesel [27], that can be used to satisfy both, the large-scale reintroduction of microalgae to bleached scleractinians with selected microalgae adapted to high temperatures [86] and local biodiesel needs. The combination of a coral reef rescue plan and a blue growth project to partially deliver the fuel to local economics promoters could be an optimal solution in the complex framework of a restoration plan (Figure 4). In many tropical or subtropical areas these marine microalgae are screened (e.g., Mauritius, Morocco or Indonesia $[17,87])$ and can provide an alternative to fossil fuel energy distribution. Taking into account the distribution of tropical coral reefs in the world and their importance to local economies, this complementary solution (i.e., saving the reefs and its potential carbon retention and energy availability in remote and poor areas) can make a great contribution to sustainable development.

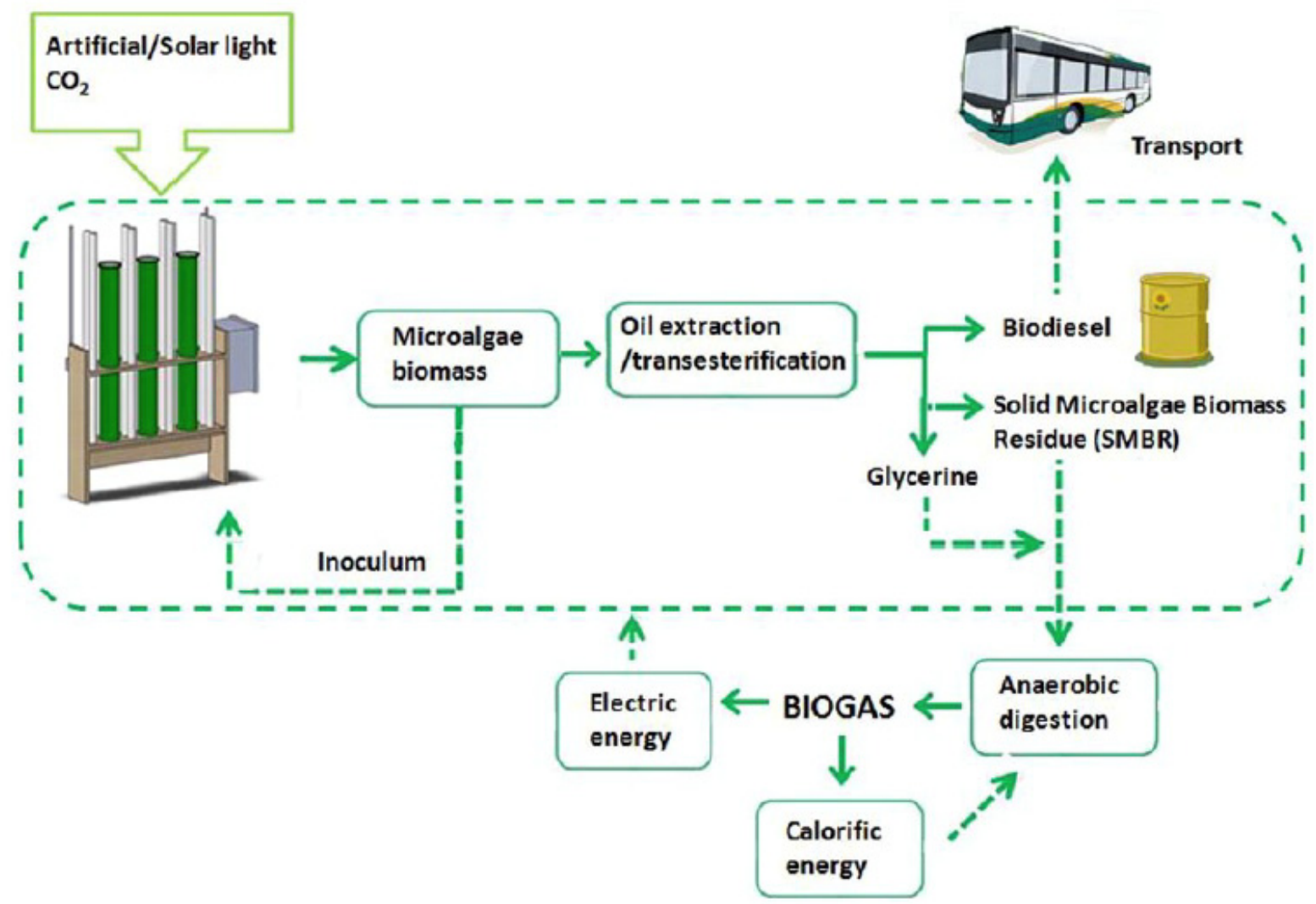

Figure 3. Producing biofuels or other by-products with Symbiodinaceae. Schematic process of biofuel (biodiesel and biogas) production from microalgae biomass; the bioreactors will permanently generate energetic products (or other substances) that can be used in local economies; when a bleaching event occurs, the local government, with the help of the local population, may use part of the production to restore the before-bleaching conditions of the scleractinians (from [49]). 


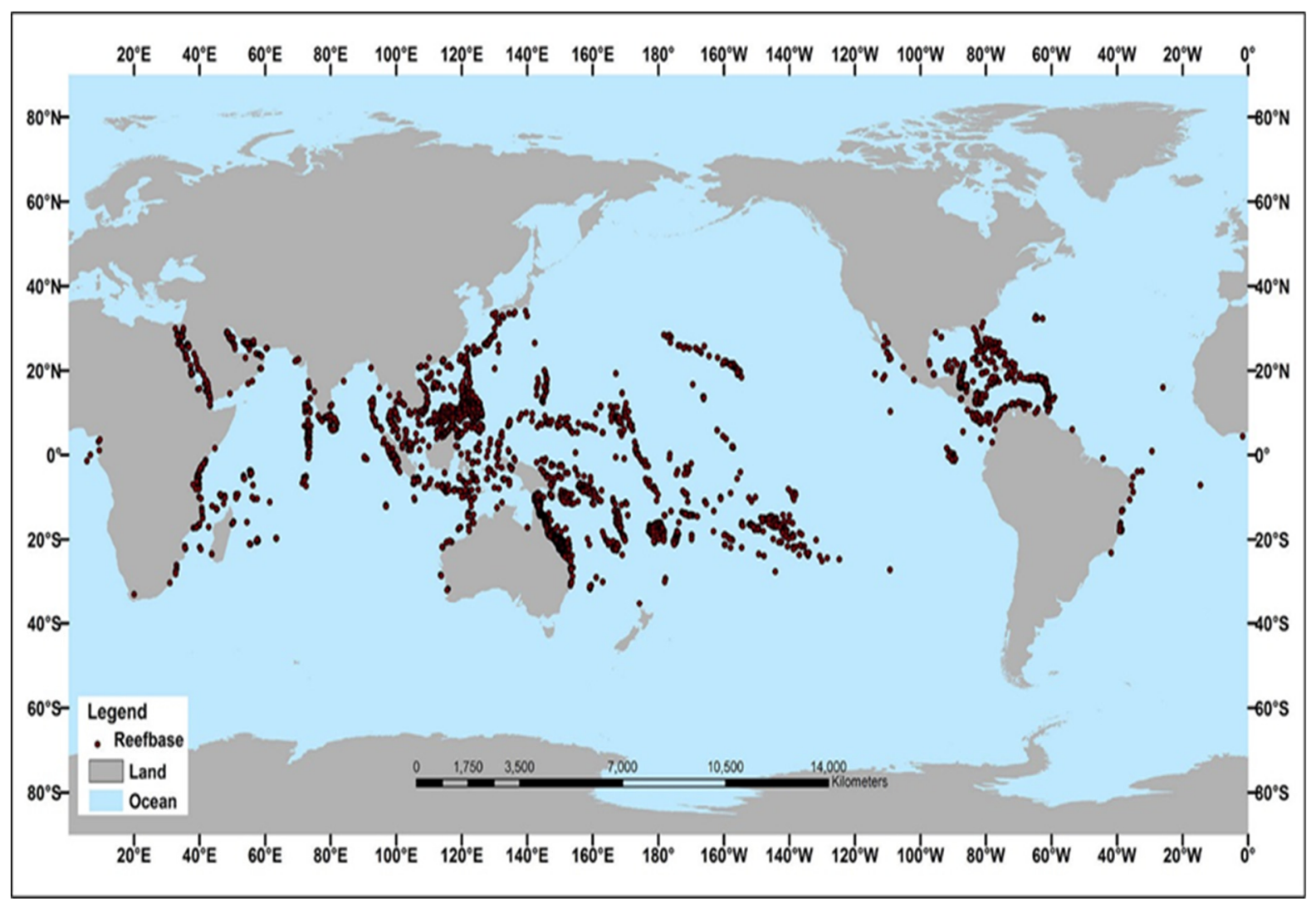

Figure 4. Map of the potential use of this methodology, highlighting the importance of the biofuel production in tropical areas where the energetic crisis will be much harder in future decades (map from NOAA Service of Education).

\section{Discussion}

Table 2 summarizes the results obtained from the upscaling test of microalgae biodiesel production to satisfy the energy need at the different number of households. To satisfy the energy requirement of one household of $178 \mathrm{GJ}$ per year, 0.11 hectares of cultivation surface and 17,400 L per year of water are needed. This represents only a small part of surface and therefore the production is feasible in terms of space. At the same time, 13.35 tons of GHGs emissions are saved relative to a petroleum diesel baseline. Responding to the energy needs of 1000 and 10,000 households the surface is still reasonable. The need for water imposes relatively high freshwater requirements that could limit the feasibility at these levels [27]. However, precipitation and the possibility of recycling the water used for cultivation must be taken into consideration. These have the potential to reduce the water requirements of the process. To satisfy the diesel energy need of 500,000 households, both surface and water required to produce biodiesel are too high compared to the amount of energy provided. Additionally, the study performed by Stephenson et al. [11] considers the annual rainfall in the UK and therefore in areas where the precipitations are lower and the evaporation is higher, greater amounts of water will be required. Thus, the freshwater requirement is one of the main factors that limit the large-scale feasibility of microalgae biofuel production [5]. The results considering the productivity yield from the study of Batan et al. [46] show even higher surface requirements to meet annual energy need.

Despite this, it is important to consider that microalgae biodiesel does not require fertile land for its production and therefore, non-arable, contaminated or abandoned land can be used for its growth. Furthermore, the microalgae grown in photobioreactors do not need soil and can be cultivated vertically as along the facades of the building, reducing the requirement for surface [69]. Therefore, biodiesel production will not compete with land for food production and no deforestation will be required to provide additional surface for cultivation. Moreover, the limits imposed by the excessive water need can be partly solved 
by considering the improvements suggested by several studies such as the utilization of wastewater and seawater. As wastewater supply could set limits, the cultivation into seawater seems to be the most promising method to produce microalgae biofuels. This study suggests that populations close to the sea could definitively be the most favored with the production of third-generation biodiesel. The use of marine microalgae is not only possible but has been demonstrated to be highly productive $[9,10]$, and the problem of the freshwater supply is reduced. Under such conditions, those small towns or villages that are near a supply of salt water (i.e., near the coast) can benefit from an unlimited water resource that will be advantageous for the productivity of biofuels.

Table 2. Land and water requirements for microalgae biodiesel production.

\begin{tabular}{cccccc}
\hline $\begin{array}{c}\text { Number of } \\
\text { Households }\end{array}$ & $\mathbf{1}$ & $\mathbf{1 0 0 0}$ & $\mathbf{1 0 , 0 0 0}$ & $\mathbf{5 0 0 , 0 0 0}$ & Refs. \\
\hline $\begin{array}{c}\text { Diesel consumption } \\
\text { per year (GJ) }\end{array}$ & 178 & 178,000 & $1,780,000$ & $89,000,000$ & - \\
\hline $\begin{array}{c}\text { Land requirement per } \\
\text { year (ha) }\end{array}$ & 0.11 & 114.63 & 1146.32 & 57,316 & {$[11]$} \\
\hline $\begin{array}{c}\text { Land requirement per } \\
\text { year (ha) }\end{array}$ & 0.13 & 125.49 & 1254.9 & 62,745 & {$[46]$} \\
\hline $\begin{array}{c}\text { Water requirement per } \\
\text { year (L) }\end{array}$ & 17,400 & $1.74 \times 10^{7}$ & $1.74 \times 10^{8}$ & $8.7 \times 10^{9}$ & {$[11]$} \\
\hline $\begin{array}{c}\text { Net GHG emissions } \\
\text { per year (tCO } \text {-eq) }\end{array}$ & -13.35 & $-13,350$ & $-133,500$ & $-6,675,000$ & {$[46]$} \\
\hline
\end{tabular}

However, a relatively small amount of fresh water is needed to compensate for the evaporative losses and to wash the biomass from salt before the oil extraction. For this reason, the selection of location to minimize evaporation such as shallow seas, saline lakes, and marine wetlands, is essential [5]. An additional benefit is that when more biodiesel is produced, greater amounts of GHGs will be saved [46]. Producing biofuel for 10,000 households will reduce 133,500 tons of GHGs from being released into the atmosphere compared to petroleum diesel.

The results of this analysis suggest that the production of biofuel from microalgae (both marine and freshwater) has the potential to satisfy the local energy needs of a certain number of households, contributing to diversifying the energy supply of a country and improving the energy security, as it represents a sustainable way to provide energy at the local level. Although excessive amounts of microalgae biomass need to be produced to satisfy relatively small energy demand, microalgae represent just a part of the solution and play an important role in energy diversification of a region and in the drive to find new sources of renewable energy. Most of the work has focused on freshwater microalgae because they are slightly easier to manage, but new perspectives on co-cultivation and use of these microorganisms are rapidly growing, making application more and more possible [15].

With the growth of the population and the related energy demand, a transition to clean energy without damaging the environment becomes more difficult. Nowadays, the world is producing each year 8 billion times more MWh of clean energy than in 2000, but the world's energy demand has increased by about 48 billion MWh, at the same time [88]. Despite it is technically feasible to upscale the amount of clean energy produced to satisfy the increase in the energy demand, it is less clear if it will be possible to do it fast enough to respect the carbon budget and follow the growing economy [88]. For these reasons, the efforts in finding the best energy sources must go together with the effort to reduce our consumption.

Despite the high cost and other unresolved issues, microalgae biofuels still perform better than terrestrial biofuels in both terms of energy and water footprint [27]. Further- 
more, as discussed in the first section, while producing renewable energy, microalgae can contribute to the achievement of important SDGs, which is an interest of our society. They have great potentials for improvements and represent an opportunity for countries to expand their energy mix and to improve energy stability and security. Thus, the petroleum sources are finite and the increase in oil prices due to the proximity of the oil peak is a reality that is approaching [89]. Additionally, the need to develop alternatives and more sustainable fuels is driven by the increasing energy demand and global warming associated with the burning of fossil fuels [5]. Finally, if we consider the possibility of applying marine microalgae to the equation, the benefits are markedly increased due to the minimal freshwater footprint [27] and the high rentability of several studied species $[17,53,90]$.

These reasons underline the importance of continuing to study the sustainable production of algal biofuels beyond their economic and technical limits, especially with marine algae. Despite the difficulty of upscaling due to the surface, water, and financial needs, it is essential to consider all the other environmental and social benefits to understand the entire sustainability of this technology. So far, these benefits have been neglected in a great part of the research on the feasibility of microalgae-based biofuels.

\section{Conclusions}

Microalgae contribute to sustainable development thanks to their ability to absorb $\mathrm{CO}_{2}$, treat wastewater, improve food and energy security and stimulate economic growth. The application of microalgae biofuel production is broad and can be integrated with other objectives such as wastewater treatment, carbon sequestration, the production of food and products that have the potential to increase a country's well-being. Microalgae biofuel can partially replace the consumption of fossil fuels that are reaching the peak and are responsible for much of the current global GHGs emissions and related climate warming. Through these applications, the development, production and use of biofuels from microalgae contributes to the achievement of important SDGs of the 2030 Agenda. From this study it is concluded that the large-scale microalgae biofuels production still faces many challenges, mainly from the economic side. However, there is a great potential to implement a small-scale production, enabling diversification of energy supply, increasing energy security and global sustainability. We are not arguing that microalgae are the solution to the deep energy problems facing humanity, but these microorganisms could be part of the solution we are looking for, especially in isolated or developing areas. The cultivation of marine microalgae is among the best solutions to overcome important barriers such as water and the space necessary for production. Authors argue the need for development in technologies, further research and the upscale of production to better test the feasibility. In particular, the most important challenge to be addressed is the supply of nutrients and the energy consumption during the production phase of biofuels. Further research needs to address the improvement of integration of microalgae cultivation with wastewater treatment, $\mathrm{CO}_{2}$ uptake from industry and the production of high-value products. This would improve implementation and can help to make microalgae biofuels (especially those from marine microalgae) a new substitute for fossil fuels, increasing energy security and environmental sustainability. In this era of environmental crisis and increased energy demand, it is essential that the evaluation of the profitability of this technology is accompanied by a series of socio-economic indicators, which not only benefit the industry, but also interest the general public. Consideration of other potential advantages for employment, environmental conservation, social acceptability, and energy security is essential to benefit each stakeholder in our society and to pursue sustainable development.

Author Contributions: Conceptualization, S.M. and S.R.; methodology, S.M.; formal analysis, S.M. and S.R.; investigation, S.M. and S.R.; writing-original draft preparation, S.M. and S.R.; writingreview and editing, S.M., X.G.D., A.P.T. and S.R.; supervision, S.R., X.G.D. and A.P.T. All authors have read and agreed to the published version of the manuscript.

Funding: This research received no external funding. 
Institutional Review Board Statement: Not applicable.

Informed Consent Statement: Not applicable.

Data Availability Statement: Not applicable.

Acknowledgments: We are grateful with the three referees who greatly improved this review.

Conflicts of Interest: The authors declare no conflict of interest.

\section{References}

1. Steffen, W.; Richardson, K.; Rockström, J.; Cornell, S.E.; Fetzer, I.; Bennett, E.M.; Biggs, R.; Carpenter, S.R.; De Vries, W.; De Wit, C.A. Planetary boundaries: Guiding human development on a changing planet. Science 2015, 347, 1259855. [CrossRef] [PubMed]

2. Lam, M.K.; Lee, K.T. Microalgae biofuels: A critical review of issues, problems and the way forward. Biotechnol. Adv. 2012, 30, 673-690. [CrossRef] [PubMed]

3. Chisti, Y. Biodiesel from microalgae. Biotechnol. Adv. 2007, 25, 294-306. [CrossRef] [PubMed]

4. Oncel, S.S. Microalgae for a macroenergy world. Renew. Sustain. Energy Rev. 2013, 26, 241-264. [CrossRef]

5. Chisti, Y. Constraints to commercialization of algal fuels. J. Biotechnol. 2013, 167, 201-214. [CrossRef]

6. Saifullah, A.Z.; Karim, M.A.; Ahmad-Yazid, A. Microalgae: An alternative source of renewable energy. Am. J. Eng. Res. 2014, 3, 330-338.

7. Greene, C.H.; Huntley, M.E.; Archibald, I.; Gerber, L.N.; Sills, D.L.; Granados, J.; Tester, J.W.; Beal, C.M.; Walsh, M.J.; Bidigare, R.R.; et al. Marine microalgae: Climate, energy, and food security from the sea. Oceanography 2016, 29, 10-15. [CrossRef]

8. Venkatesan, J.; Manivasagan, P.; Kim, S.K. Chapter 1-Marine microalgae biotechnology: Present trends and future advances. In Handbook of Marine Microalgae; Academic Press: Cambridge, UK, 2015; pp. 1-9.

9. Itoiz, E.S.; Fuentes-Grünewald, C.; Gasol, C.M.; Garcés, E.; Alacid, E.; Rossi, S.; Rieradevall, J. Energy balance and environmental impact analysis of marine microalgal biomass production for biodiesel generation in a photobioreactor pilot plant. Biomass Bioenergy 2012, 39, 324-335. [CrossRef]

10. Fuentes-Grünewald, C.; Garcés, E.; Alacid, E.; Sampedro, N.; Rossi, S.; Camp, J. Improvement of lipid production in the marine strains Alexandrium minutum and Heterosigma akashiwo by utilizing abiotic parameters. J. Ind. Microbiol. Biotechnol. 2012, 39, 207-216. [CrossRef]

11. Stephenson, A.L.; Kazamia, E.; Dennis, J.S.; Howe, C.J.; Scott, S.A.; Smith, A.G. Life-Cycle assessment of potential algal biodiesel production in the United Kingdom: A comparison of raceways and air-lift tubular bioreactors. Energy Fuels 2010, 24, 4062-4077. [CrossRef]

12. Benemann, J.; Woertz, I.; Lundquist, T. Life cycle assessment for microalgae oil production. Disruptive Sci. Technol. 2012, 1, 68-78. [CrossRef]

13. Ketzer, F.; Skarka, J.; Rösch, C. Critical review of microalgae LCA studies for bioenergy production. Bioenergy Res. 2017, 11, 95-105. [CrossRef]

14. Greene, C.H.; Huntley, M.E.; Archibald, I.; Gerber, L.N.; Sills, D.L.; Granados, J.; Beal, C.M.; Walsh, M.J. Geoengineering, marine microalgae, and climate stabilization in the 21st century. Earth's Future 2017, 5, 278-284. [CrossRef]

15. de Almeida Moreira, B.R.; de Almeida Viana, C.R.; Cruz, V.H.; Lopes, P.R.M.; da Silva Viana, R.; Ramos, R.A.V. Meta-Analytic review on third-generation biodiesel. Bioenergy Res. 2021, 1-19.

16. Sakthivel, R.; Ramesh, K.; Purnachandran, R.; Shameer, P.M. A review on the properties, performance and emission aspects of the third generation biodiesels. Renew. Sustain. Energy Rev. 2018, 82, 2970-2992. [CrossRef]

17. Suripto, S.; Japa, L. Consortium of wallacean microalgae in West Nusa Tenggara for biodiesel production. J. Biol. Trop. 2018, 18, 224-229.

18. Cheregi, O.; Ekendahl, S.; Engelbrektsson, J.; Strömberg, N.; Godhe, A.; Spetea, C. Microalgae biotechnology in Nordic countriesthe potential of local strains. Physiol. Plant. 2019, 166, 438-450. [CrossRef] [PubMed]

19. Arroussi, H.E.; Benhima, R.; Mernissi, N.E.; Bouhfid, R.; Tilsaghani, C.; Bennis, I.; Wahby, I. Screening of marine microalgae strains from Moroccan coasts for biodiesel production. Renew. Energy 2017, 113, 1515-1522. [CrossRef]

20. Teymouri, A.; Kumar, S.; Barbera, E.; Sforza, E.; Bertucco, A.; Morosinotto, T. Integration of biofuels intermediates production and nutrients recycling in the processing of a marine algae. AIChE J. 2017, 63, 1494-1502. [CrossRef]

21. Peng, L.; Fu, D.; Chu, H.; Wang, Z.; Qi, H. Biofuel production from microalgae: A review. Environ. Chem. Lett. 2020, 18, 285-297. [CrossRef]

22. United Nations. The Sustainable Development Goals Report 2018; UN Publications: New York, NY, USA, 2018 ; pp. 4-15.

23. Mata, T.M.; Martins, A.A.; Caetano, N.S. Microalgae for biodiesel production and other applications: A review. Renew. Sustain. Energy Rev. 2010, 14, 217-232. [CrossRef]

24. Lead, C. Climate and Environmental Change in the Mediterranean Basin-Current Situation and Risks for the Future. In Union for the Mediterranean, Plan Bleu; UNEP/MAP: Marseille, France, 2020.

25. Acién Fernández, F.; González-López, C.; Fernández Sevilla, J.; Molina Grima, E. Conversion of $\mathrm{CO}_{2}$ into biomass by microalgae: How realistic a contribution may it be to significant $\mathrm{CO}_{2}$ removal? Appl. Microbiol. Biotechnol. 2012, 96, 577-586. [CrossRef] 
26. Zhou, W.; Wang, J.; Chen, P.; Ji, C.; Kang, Q.; Lu, B.; Ruan, R. Bio-mitigation of carbon dioxide using microalgal systems: Advances and perspectives. Renew. Sustain. Energy Rev. 2017, 76, 1163-1175. [CrossRef]

27. Maeda, Y.; Yoshino, T.; Matsunaga, T.; Matsumoto, M.; Tanaka, T. Marine microalgae for production of biofuels and chemicals. Curr. Opin. Biotechnol. 2018, 50, 111-120. [CrossRef]

28. Rizwan, M.; Mujtaba, G.; Memon, S.A.; Lee, K.; Rashid, N. Exploring the potential of microalgae for new biotechnology applications and beyond: A review. Renew. Sustain. Energy Rev. 2018, 92, 394-404. [CrossRef]

29. Sayre, R. Microalgae: The potential for carbon capture. BioScience 2010, 60, 722-727. [CrossRef]

30. Ramanan, R.; Kannan, K.; Deshkar, A.; Yadav, R.; Chakrabarti, T. Enhanced algal $\mathrm{CO}_{2}$ sequestration through calcite deposition by Chlorella sp. and Spirulina platensis in a mini-raceway pond. Bioresour. Technol. 2010, 101, 2616-2622. [CrossRef]

31. Kishimoto, M.; Okakura, T.; Nagashima, H.; Minowa, T.; Yokoyama, S.Y.; Yamaberi, K. $\mathrm{CO}_{2}$ fixation and oil production using micro-algae. J. Ferment. Bioeng. 1994, 78, 479-482. [CrossRef]

32. Chiu, S.Y.; Kao, C.Y.; Tsai, M.T.; Ong, S.C.; Chen, C.H.; Lin, C.S. Lipid accumulation and $\mathrm{CO}_{2}$ utilization of Nannochloropsis oculata in response to CO2 aeration. Bioresour. Technol. 2009, 100, 833-838. [CrossRef]

33. Ono, E.; Cuello, J.L. Carbon dioxide mitigation using thermophilic cyanobacteria. Biosyst. Eng. 2007, 96, 129-134. [CrossRef]

34. Jacob-Lopes, E.; Revah, S.; Hernández, S.; Shirai, K.; Franco, T.T. Development of operational strategies to remove carbon dioxide in photobioreactors. Chem. Eng. J. 2009, 153, 120-126. [CrossRef]

35. Jacob-Lopes, E.; Lacerda, L.M.; Franco, T.T. Biomass production and carbon dioxide fixation by Aphanothece microscopica Nägeli in a bubble column photobioreactor. Biochem. Eng. J. 2008, 40, 27-34. [CrossRef]

36. López, C.G.; Fernández, F.A.; Sevilla, J.F.; Fernández, J.S.; García, M.C.; Grima, E.M. Utilization of the cyanobacteria Anabaena sp. ATCC 33047 in $\mathrm{CO}_{2}$ removal processes. Bioresour. Technol. 2009, 100, 5904-5910. [CrossRef]

37. Chiang, C.L.; Lee, C.M.; Chen, P.C. Utilization of the cyanobacteria Anabaena sp. CH1 in biological carbon dioxide mitigation processes. Bioresour. Technol. 2011, 102, 5400-5405. [CrossRef]

38. Sydney, E.B.; Sturm, W.; de Carvalho, J.C.; Thomaz-Soccol, V.; Larroche, C.; Pandey, A.; Soccol, C.R. Potential carbon dioxide fixation by industrially important microalgae. Bioresour. Technol. 2010, 101, 5892-5896. [CrossRef] [PubMed]

39. Chiu, S.Y.; Kao, C.Y.; Chen, C.H.; Kuan, T.C.; Ong, S.C.; Lin, C.S. Reduction of $\mathrm{CO}_{2}$ by a high-density culture of Chlorella sp. in a semicontinuous photobioreactor. Bioresour. Technol. 2008, 99, 3389-3396. [CrossRef]

40. Cheah, W.; Ling, T.; Juan, J.; Lee, D.; Chang, J.; Show, P. Biorefineries of carbon dioxide: From carbon capture and storage (CCS) to bioenergies production. Bioresour. Technol. 2016, 215, 346-356. [CrossRef] [PubMed]

41. Fan, L.H.; Zhang, Y.T.; Zhang, L.; Chen, H.L. Evaluation of a membrane-sparged helical tubular photobioreactor for carbon dioxide biofixation by Chlorella vulgaris. J. Membr. Sci. 2008, 325, 336-345. [CrossRef]

42. Huntley, M.E.; Redalje, D.G. $\mathrm{CO}_{2}$ mitigation and renewable oil from photosynthetic microbes: A new appraisal. Mitig. Adapt. Strateg. Glob. Chang. 2007, 12, 573-608. [CrossRef]

43. Yun, Y.S.; Lee, S.B.; Park, J.M.; Lee, C.I.; Yang, J.W. Carbon dioxide fixation by algal cultivation using wastewater nutrients. J. Chem. Technol. Biotechnol. Int. Res. Process Environ. Clean Technol. 1997, 69, 451-455. [CrossRef]

44. Chisti, Y. Response to Reijnders: Do biofuels from microalgae beat biofuels from terrestrial plants? Trends Biotechnol. 2008, 26, 351-352. [CrossRef]

45. Maity, J.P.; Bundschuh, J.; Chen, C.; Bhattacharya, P. Microalgae for third generation biofuel production, mitigation of greenhouse gas emissions and wastewater treatment: Present and future perspectives-A mini review. Energy 2014, 78, 104-113. [CrossRef]

46. Batan, L.; Quinn, J.; Willson, B.; Bradley, T. Net energy and greenhouse gas emission evaluation of biodiesel derived from microalgae. Environ. Sci. Technol. 2010, 44, 7975-7980. [CrossRef]

47. Milano, J.; Ong, H.C.; Masjuki, H.; Chong, W.; Lam, M.K.; Loh, P.K.; Vellayan, V. Microalgae biofuels as an alternative to fossil fuel for power generation. Renew. Sustain. Energy Rev. 2016, 58, 180-197. [CrossRef]

48. Medeiros, D.L.; Sales, E.A.; Kiperstok, A. Energy production from microalgae biomass: Carbon footprint and energy balance. J. Clean. Prod. 2015, 96, 493-500. [CrossRef]

49. Santos-Ballardo, D.U.; Font-Segura, X.; Ferrer, A.S.; Barrena, R.; Rossi, S.; Valdez-Ortiz, A. Valorisation of biodiesel production wastes: Anaerobic digestion of residual Tetraselmis suecica biomass and co-digestion with glycerol. Waste Manag. Res. 2015, 33, 250-257. [CrossRef]

50. Santos-Ballardo, D.U.; Rossi, S.; Reyes-Moreno, C.; Valdez-Ortiz, A. Microalgae potential as a biogas source: Current status, restraints and future trends. Rev. Environ. Sci. Bio/Technol. 2016, 15, 243-264. [CrossRef]

51. Abdel-Raouf, N.; Al-Homaidan, A.; Ibraheem, I. Microalgae and wastewater treatment. Saudi J. Biol. Sci. 2012, 19, 257-275. [CrossRef]

52. Moody, J.W.; McGinty, C.M.; Quinn, J.C. Global evaluation of biofuel potential from microalgae. Proc. Natl. Acad. Sci. USA 2014, 111, 8691-8696. [CrossRef]

53. Fuentes-Grünewald, C.; Garcés, E.; Alacid, E.; Rossi, S.; Camp, J. Biomass and lipid production of dinoflagellates and raphidophytes in indoor and outdoor photobioreactors. Mar. Biotechnol. 2013, 15, 37-47. [CrossRef]

54. Zienkiewicz, K.; Du, Z.Y.; Ma, W.; Vollheyde, K.; Benning, C. Stress-induced neutral lipid biosynthesis in microalgae-Molecular, cellular and physiological insights. Biochim. Biophys. Acta (BBA) Mol. Cell Biol. Lipids 2016, 1861, 1269-1281. [CrossRef] 
55. Zhang, Y.; Kendall, A. Consequential analysis of algal biofuels: Benefits to ocean resources. J. Clean. Prod. 2019, 231, 35-42. [CrossRef]

56. Gonçalves, A.; Pires, J.; Simões, M. A review on the use of microalgal consortia for wastewater treatment. Algal Res. 2017, 24, 403-415. [CrossRef]

57. Razzak, S.A.; Ali, S.A.; Hossain, M.M.; Delasa, H. Biological $\mathrm{CO}_{2}$ fixation with production of microalgae in wastewater-A review. Renew. Sustain. Energy Rev. 2017, 76, 379-390. [CrossRef]

58. Mcginn, P.J.; Dickinson, K.E.; Bhatti, S.; Frigon, J.; Guiot, S.R.; O'Leary, S.J. Erratum to: Integration of microalgae cultivation with industrial waste remediation for biofuel and bioenergy production: Opportunities and limitations. Photosynth. Res. 2011, 109, 249. [CrossRef]

59. Christenson, L.; Sims, R. Production and harvesting of microalgae for wastewater treatment, biofuels, and bioproducts. Biotechnol. Adv. 2011, 29, 686-702. [CrossRef]

60. Quiroz Arita, C.; Peebles, C.; Bradley, T. Scalability of combining microalgae-based biofuels with wastewater facilities: A review. Algal Res. 2015, 9, 160-169. [CrossRef]

61. Salama, E.; Kurade, M.B.; Abou-Shanab, R.A.; El-Dalatony, M.M.; Yang, I.; Min, B.; Jeon, B. Recent progress in microalgal biomass production coupled with wastewater treatment for biofuel generation. Renew. Sustain. Energy Rev. 2017, 79, 1189-1211. [CrossRef]

62. Adenle, A.; Haslam, G.; Lee, L. Global assessment of research and development for algae biofuel production and its potential role for sustainable development in developing countries. Energy Policy 2013, 61, 182-195. [CrossRef]

63. Efroymson, R.; Dale, V.; Langholtz, M. Socioeconomic indicators for sustainable design and commercial development of algal biofuel systems. GCB Bioenergy 2016, 9, 1005-1023. [CrossRef]

64. García, J.; de Vicente, M.; Galán, B. Microalgae, old sustainable food and fashion nutraceuticals. Microb. Biotechnol. 2017, 10, 1017-1024. [CrossRef]

65. Antenna.ch. Spirulina Production-Antenna Foundation. 2019. Available online: https://www.antenna.ch/en/activities/ nutrition/spirulina-production/ (accessed on 15 June 2019).

66. Park, H.; Lee, C.G. Theoretical calculations on the feasibility of microalgal biofuels: Utilization of marine resources could help realizing the potential of microalgae. Biotechnol. J. 2016, 11, 1461-1470. [CrossRef]

67. Wilkinson, S.; Stoller, P.; Ralph, P.; Hamdorf, B.; Catana, L.N.; Kuzava, G.S. Exploring the Feasibility of Algae Building Technology in NSW. Procedia Eng. 2017, 180, 1121-1130. [CrossRef]

68. Elrayies, G. Microalgae: Prospects for greener future buildings. Renew. Sustain. Energy Rev. 2018, 81, 1175-1191. [CrossRef]

69. Pruvost, J.; Le Gouic, B.; Lepine, O.; Legrand, J.; Le Borgne, F. Microalgae culture in building-integrated photobioreactors: Biomass production modelling and energetic analysis. Chem. Eng. J. 2016, 284, 850-861. [CrossRef]

70. Morales, M.; Collet, P.; Lardon, L.; Hélias, A.; Steyer, J.P.; Bernard, O. Life-cycle assessment of microalgal-based biofuel. In Biomass, Biofuels and Biochemicals; Elsevier: Cambridge, UK, 2019; pp. 507-550.

71. Jorquera, O.; Kiperstok, A.; Sales, E.A.; Embiruçu, M.; Ghirardi, M.L. Comparative energy life-cycle analyses of microalgal biomass production in open ponds and photobioreactors. Bioresour. Technol. 2010, 101, 1406-1413. [CrossRef]

72. Fuad, N.; Omar, R.; Kamarudin, S.; Harun, R.; Idris, A.; Wan Azlina, W.A.K.G. Mass harvesting of marine microalgae using different techniques. Food Bioprod. Process. 2018, 112, 169-184. [CrossRef]

73. Jiang, Y.; Yoshida, T.; Quigg, A. Photosynthetic performance, lipid production and biomass composition in response to nitrogen limitation in marine microalgae. Plant Physiol. Biochem. 2012, 54, 70-77. [CrossRef]

74. Sukačová, K.; Lošák, P.; Brummer, V.; Máša, V.; Vícha, D.; Zavřel, T. Perspective design of algae photobioreactor for greenhousesA comparative study. Energies 2021, 14, 1338. [CrossRef]

75. Van Duren, I.; Voinov, A.; Arodudu, O.; Firrisa, M.T. Where to produce rapeseed biodiesel and why? Mapping European rapeseed energy efficiency. Renew. Energy 2015, 74, 49-59. [CrossRef]

76. Sezione Della Protezione Dell'aria, Dell'acqua e del Suolo, Ufficio Dell'energia, Istituto di Sostenibilità Applicate All'ambiente Costruito. Consumi di Energia (in Gigawattora), Secondo la Destinazione e il Vettore Energetico, in Ticino, Nel 2015. Available online: https: / www3.ti.ch/DFE/DR/USTAT/index.php?fuseaction=temi.sottotema\&p1=44\&p2=300\&p3=301\&proId=300 (accessed on 15 December 2017).

77. International Energy Agency. Energy Consumption in Households in 2012. Available online: https://www.iea.org/media/ statistics/eemanual/energy_consumption_in_households_in_20122.pdf (accessed on 10 July 2019).

78. Rossi, S.; Rizzo, L. Marine animal forests as carbon immobilizers or why we should preserve these three-dimensional alive structures. In Perspectives on the Marine Animal Forests of the World; Springer: Cham, Switzerland, 2020; pp. 333-400.

79. Rossi, S. The destruction of the 'animal forests' in the oceans: Towards an over-simplification of the benthic ecosystems. Ocean Coast. Manag. 2013, 84, 77-85. [CrossRef]

80. Rossi, S.; Bramanti, L.; Gori, A.; Orejas, C. An overview of the animal forests of the world. In Marine Animal Forest; Rossi, S., Ed.; Springer: Berlin, Germany, 2017; pp. 1-25.

81. Hoegh-Guldberg, O.; Mumby, P.J.; Hooten, A.J.; Steneck, R.S.; Greenfield, P.; Gomez, E.; Harvell, C.D.; Sale, P.F.; Edwards, A.J.; Caldeira, K.; et al. Coral reefs under rapid climate change and ocean acidification. Science 2007, 318, 1737-1742. [CrossRef]

82. Hughes, T.P.; Kerry, J.T.; Baird, A.H.; Connolly, S.R.; Dietzel, A.; Eakin, C.M.; Heron, S.F.; Hoey, A.S.; Hoogenboom, M.O.; Liu, G.; et al. Global warming transforms coral reef assemblages. Nature 2018, 556, 492-496. [CrossRef] [PubMed]

83. Rinkevich, B. Ecological engineering approaches in coral reef restoration. ICES J. Mar. Sci. 2020. [CrossRef] 
84. France, R.L. From land to sea: Governance-management lessons from terrestrial restoration research useful for developing and expanding social-ecological marine restoration. Ocean Coast. Manag. 2016, 133, 64-71. [CrossRef]

85. Van Oppen, M.J.; Gates, R.D.; Blackall, L.L.; Cantin, N.; Chakravarti, L.J.; Chan, W.Y.; Cormick, C.; Crean, A.; Damjanovic, K.; Epstein, H.; et al. Shifting paradigms in restoration of the world's coral reefs. Glob. Chang. Biol. 2017, 23, 3437-3448. [CrossRef]

86. Buerger, P.; Alvarez-Roa, C.; Coppin, C.W.; Pearce, S.L.; Chakravarti, L.J.; Oakeshott, J.G.; Edwards, O.R.; Van Oppen, M.J.H. Heat-evolved microalgal symbionts increase coral bleaching tolerance. Sci. Adv. 2020, 6, eaba2498. [CrossRef]

87. Beetul, K.; Bibi Sadally, S.; Taleb-Hossenkhan, N.; Bhagooli, R.; Puchooa, D. An investigation of biodiesel production from microalgae found in Mauritian waters. Biofuel Res. J. 2014, 1, 58-64. [CrossRef]

88. Hickel, J. The contradiction of the sustainable development goals: Growth versus ecology on a finite planet. Sustain. Dev. 2019, 27, 873-884. [CrossRef]

89. Turiel, A. Por Qué la Fecha Exacta del oil Peak es Irrelevante [Web Log Post]. Available online: http://crashoil.blogspot.com/20 10/06/por-que-la-fecha-exacta-del-oil-peak-es.html (accessed on 25 January 2010).

90. Rekha, V.; Gurusamy, R.; Santhanam, P.; Devi, A.S.; Ananth, S. Culture and biofuel production efficiency of marine microalgae Chlorella marina and Skeletonema costatum. Indian J. Geo-Mar. Sci. 2012, 41, 152-158. 